\title{
Investigation of Biosynthesized Silver Nano Particles Interaction From Halymenia Porphyroides With The E7 Protein Using Bioinformatics Tool
}

\author{
Vishnu Kiran $\mathbf{M}^{1}$, Murugesan $\mathbf{S}^{1 *}$ and Sivamurugan $\mathbf{V}^{2}$ \\ ${ }^{1}$ Division of Algal Biotechnology and Bio-Nanotechnology, Pachaiyappa's College, India \\ ${ }^{2} P G$ and Research Department of Chemistry, Pachaiyappa's College, India
}

Received: September 02, 2017; Published: September 15, 2017

*Corresponding author: Murugesan S, 1Division of Algal Biotechnology and Bio-Nanotechnology, PG and Research Department of Botany, Pachaiyappa's College, Chennai-600030, India, Email: smurugesan5@gmail.com

\begin{abstract}
Silver nano particles have known to possess anticancer properties in the early stages of virus proliferation. In the present study biosynthesis of silver nano particles from marine red alga Halymenia porphyroides was synthesized and characterized. Studies on protein disulphide bonds were done using Metal Detector Predicts V2.0 software. All Cys and His residues in amino acid sequences were identified. The study revealed that silver nano particles couple with the sulfhydryl groups led to decrease the disulphide bonds and denatures the E7 protein thus eliminating the possibility of the occurrence of the disease.
\end{abstract}

Keywords: Bioinformatics; E7 protein; Silver nano particles; Metal binding sites.

\section{Introduction}

Nano particles exhibit unique biological, physical and chemical properties based on specific characteristics such as shape, size, distribution and surface morphology. Synthesis of nano particles through biochemical routes, using plant and algal extracts as reducing and capping agents, has received special attention among others, due to maintaining an aseptic environment during the synthetic process [1-7]. Therefore, medicinal plants and algae having well established therapeutic importance are being widely used for the size and shape controlled synthesis of silver nano particles [8-11].

Silver nano particles are one of the most marketable nano materials, because they are extensively applied as biocides due to their strong antimicrobial activity. The silver nano particles possess high surface area enhancing the antimicrobial activity of nano particles [12] and their conductive [13], optic [14], as well as catalytic properties [15] widen their scope in many applications. Silver nano particles are also potential antiviral agents against HIV-1 [16], hepatitis B virus [17], respiratory syncytial virus [18], herpes simplex virus type 1 [19] and monkey pox virus [20]. Human papilloma viruses (HPVs) have been found in over $90 \%$ of cervical cancer, as well as in other carcinomas [21]. Certain HPV types have been classified as "high risk" types and others as "low risk", based on the clinical prognosis of lesions which they cause. The major transforming proteins of the high risk HPVs have been identified as the early proteins E6 and E7; expression of these proteins is maintained in carcinoma cells lines [22], and expression of these two proteins induces immortalization and transformation in a variety of rodent and human cell types [23]. The aim of the study was to investigate the bioinformatics prediction of interaction of the obtained silver nano particles from $H$. porphyroides corresponding to the silver with Ag formula (number 94565) from ChemSpider website on the disulphide bonds of the E7 protein (www.chemispider.com).

\section{Materials and Methods}

\section{Biosynthesis of silver nano particles}

Silver nano particles were biosynthesized from the red seaweed Halymenia porphyroides. $500 \mathrm{mg}$ of the dry seaweed was taken in $10^{-3} \mathrm{M}$ aqueous $\left(\mathrm{AgNO}_{3}\right)$ solution and the incubation was done at 35-37 0C for 24-48 hrs. The pH was checked and found to be 5.09 during the synthesis. The silver nanoparticles were characterized using UV visible spectroscopy, X-Ray diffraction studies, FT-IR spectroscopy, Scanning Electron Microscopy and HR- Transmission Electron Microscopy.

\section{Proteome analysis and modelling of the E7 protein using SWISSPDBV}

The specific disease selection and all the proteins involved in the pathway are surveyed from KEGG database. The amino acid 
sequence of the selected protein for cancer is E7 protein which was obtained from Swissprot. The existing template modelled designed structures were searched in PDB. Since there is no model available in PDB, Swiss model and Ramachandran plot were created. For this purpose swisspd bv was used. A login ID was created in SWISS MODEL. AUTOMATED mode was selected for designing. The raw amino acid sequence of E7 was submitted. BLASTp was run to determine the most similar template for E7. The programmer was run to predict the most effective structure. The Ramachandran plot was constructed to find out the stability, as well as the alignment of all the amino acids. The overall quality of the modelled protein was checked by logging on to structure verification server site (SAVS). The target molecule file was uploaded to the SAVS. The SAVS process the molecule and interpret the results. The problematic amino acids, overall quality factor and other results were obtained. The modelled protein was obtained and the structure variation is viewed through SPDV.

\section{Studying disulphide bonds in proteins}

The web server Metal Detector is freely available at (http:// metaldetector.dsi.unifi.it/v2.0) which classifies histidine residues in proteins into two states (free or metal bound) and cysteine's into three states (free, metal bound or disulphide bridged). This web server takes the protein sequence as input and provides predictions of transition-metal binding sites for cysteine and histidine residues as output; for cysteine it also predicts disulphide bonding bridges. The residues were predicted to coordinate the same ion and will also share the same identifier. Every identifier is an integer ranging from 1 to 4 . Its value has no special biochemical semantics but lower value corresponds to a higher level of confidence for the predictor.

\section{Studying of disulphide bonds}

The studies on disulphide bonds were performed using Metal Detector Predicts v2.0 software. All Cys and His residues in amino acid sequences were identified. (http://metaldetector.dsi.unifi.it).

\section{Results and Discussion}

\section{Silver nano particles and their characterization}

Biosynthesis of silver nanoparticles from the red seaweed Halymenia porphyroides extract was formed by the reduction of $\mathrm{Ag}^{+}$at 35-370C. The change in pale yellow to brown colour change indicated the formation of silver nano particles in the solution and confirmed the excitation of surface plasmon vibrations during the formation of silver nano particles. The biosynthesized silver nano particles was thoroughly characterized and was presented in our previous investigation.

The absorption peak at $420 \mathrm{~nm}$ in the UV-visible spectroscopy showed AgNPs formation and confirmation of surface plasmon resonance [24]. The vibrations peaks from 2354.71 to $3884.4 \mathrm{~cm}^{-1}$ from the FT-IR spectrum analysis indicated the presence of several functional moieties of organic compounds associated with silver nano particles. The various organic compounds present were O-H groups, free alcohol groups, free amines and intra molecular hydrogen bonds. The secondary metabolites such as flavanoids, alkaloids, terpenoids and steroids could possibly act as capping ligand for stabilization of the silver nano particles [25]. The SEM analysis of the biosynthesized silver nano particles showed the average size of the particles and was in spherical shape. The formation of the stable spherical and isotropic nano particles maybe due to the biomolecules associated with the silver nano particles [26].

The HR-TEM images of mediated silver nanoparticle synthesis showed the formation of spherical shaped silver nano particles (Figure 1). The size of the biosynthesized silver nano particles ranged between 5 to $50 \mathrm{~nm}$ and the average mean size of silver nano particles was $32 \mathrm{~nm}$.

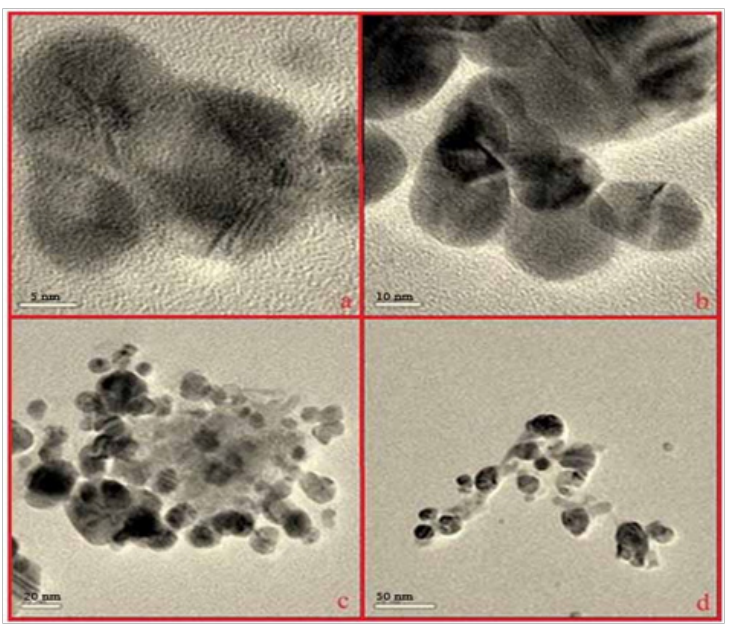

Figure 1: HR-TEM images of silver nano particles of biosynthesized H. porphyroides. (a) $5 \mathrm{~nm}$ (b) $10 \mathrm{~nm}$ (c) 20 $\mathrm{nm}$ (d) $50 \mathrm{~nm}$.

\section{Protein structure analysis}

The Swissprot was used to identify the amino acid sequence of the selected protein for cancer E7 protein (Figure 2). The stability and the alignment of the amino acids were confirmed by constructing the Ramachandran plot (Figure 3). SPDV was used to see the structure variation and the constructed modelled protein (Figure 4). E7 protein structure contains chain A and chain B and its length is 371 amino acids, and its molecular weight is $17 \mathrm{kD}$. Over $90 \%$ of malignant carcinomas of the genital tract have HPV DNA sequences; the majority of which contain the high risk HPV-16 and 18 types which are linked to the progression of cervical lesions. The most abundant viral transcripts in tumor and tumor cell lines come from the E6 and E7 open reading frames that are known to be oncogenic. These two genes from HPV are necessary and sufficient to induce HPV-mediated transformation of murine cells. HPV16 E7 binds to the unphosphorylated form of the retinoblastoma protein. E7 proteins of other types (HPVs 6,11,18) have also been shown to bind to pRB [27]. Silver nano particles act at the beginning stages of viral propagation (penetration or spread) and at pre-penetration stages [28]. The binding of silver ions to sulfhydryl groups causes protein denaturation through reducing disulphide bonds [29]. The results of the present study showed that the first and most important part of this protein binds E7 and pRB protein. In Molegro software the basis of the three dimensional structure of this protein is positioned between 20 to 29 amino acids where sulphide bonds 
are located. Breaking this binding can change the spatial structure of this protein, therefore prevents this part from binding with pRB.

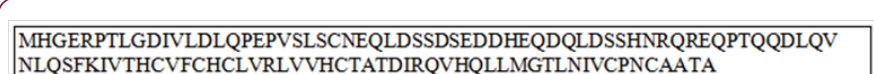

NLQSFKIVTHCVFCHCLVRLVVHCTATDIRQVHQLLMGTLNIVCPNCAATA

Figure 2: Protein sequence from Swissprot.

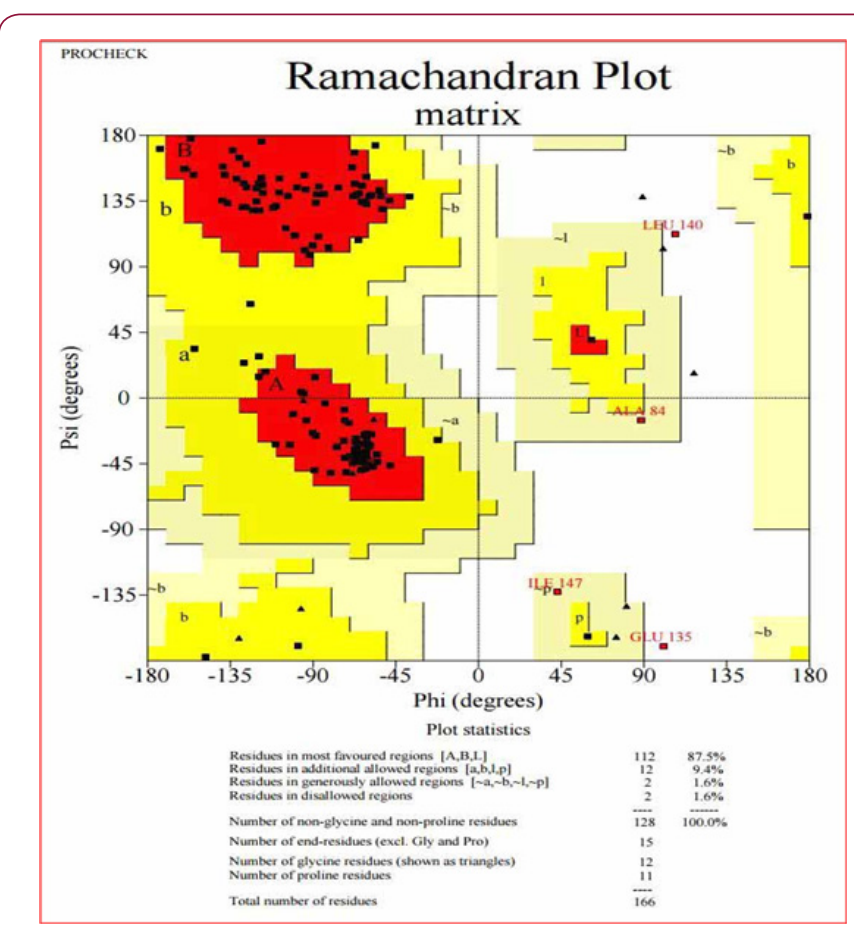

Figure 3: Ramachandran plot showing the protein clearance in SAVS.

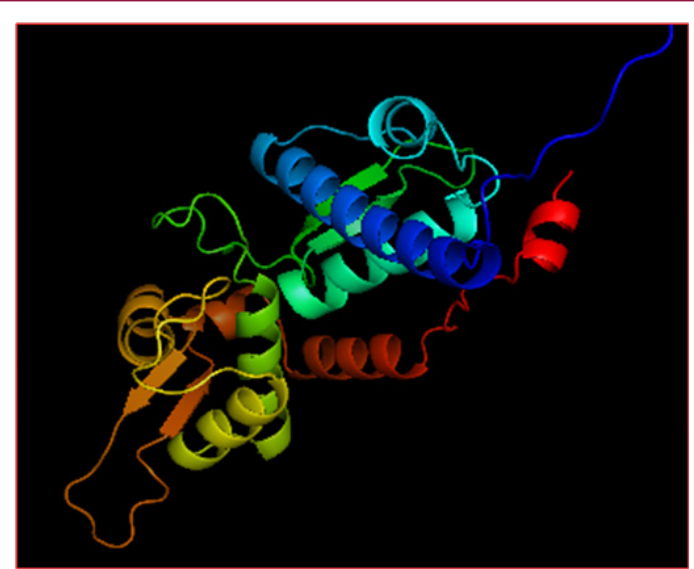

Figure 4: Modelled E7 protein structure.

According to the results taken from Metal Detector Predicts v2.0 online server, the disulphide bonds in E7 protein amino acid sequence are sited between cysteine amino acids in various locations (Figure 5). The $27^{\text {th }}$ sequence is in the first and most important part of this protein to bind E7 and pRB proteins. In Molegro software on the basis of the three dimensional structure of this protein is positioned between 20 to 29 amino acids where sulphide bonds are located. Breaking this binding can change the spatial structure of this protein and therefore, prevent this part from binding to $\mathrm{pRB}$.

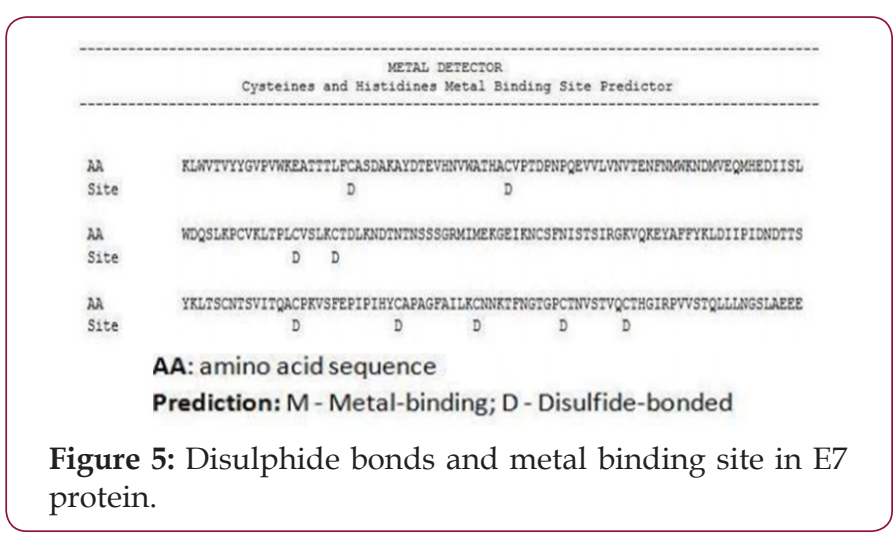

\section{Conclusion}

Silver nano particles can act as antivirus agent for deactivation of the virus in a short period of time. This process is done through interaction of nano silver with 2 disulphide bonds located in carboxyl (E7) so that silver ions, through interaction with thiol group, decrease disulphide bonds leading to protein denaturation. Considering other similar scientific investigations, one can conclude that the mentioned process is fulfilled through substitution of single valence $\mathrm{Ag}^{+}$with $\mathrm{H}^{+}$existed in thiol group. Bioinformatics results using software and servers show that silver ions make interaction with thiol group through which the disulphide bonds decrease and the virus and cancer proliferation were inhibited.

\section{References}

1. Basavaraja S, Balaji SD, Lagashetty A, Rajasab AH, Venkataraman A (2008) Extracellular biosynthesis of silver nanoparticles using the fungus Fusarium semitectum. Mater Res Bull 43: 1164-1177.

2. Gardea-Torresdey JL, Gomez E, Peralta-Videa J, Parsons JG, Troiani HE (2002) Formation and growth of Au nano particles inside live alfalfa plants. Nano Lett 2: 397-401.

3. Prathna TC, Chandrasekaran NA, Raichur M, Mukherjee A (2011) Kinetic evolution study of silver nano particles in bio-based green synthesis process. Colloids Surf A Physicochem Eng 377: 212-216.

4. Rastogi L, Arunachalam J (2011) Sunlight based irradiation strategy for rapid green synthesis of highly stable silver nano particles using aqueous garlic (Allium sativum) extract and their antibacterial potential. Mater Chem Phys 129: 558-563.

5. Liu Y, Zhang YA, Zhang M (2010) Green hydrothermal synthesis and characterization of CdO2 nanoparticles. Mater Lett 64: 1779-1781.

6. Ali MD, Thajuddin N, Jeganathan K, Gunasekaran M (2011) Plant extract mediated synthesis of silver and gold nano particles and its antibacterial activity against clinically isolated pathogens. Colloids Surf B 85: 360365.

7. Vidhu VK, Aromal SA, Philip D (2011) Green synthesis of silver nanoparticles using Macrotyloma uniflorum. Spectrochim Acta A 83: 392-397.

8. Zhan G, Huang J, Du M, Abdul-Rauf I, Ma Y, et al. (2011) Green synthesis of Au-Pd bimetallic nano particles: Single-step bioreduction method with plant extract. Mater Lett 65: 2989-2991.

9. Dubey SP, Lahtinen M, Sillanpää M (2010) Tansy fruit mediated greener synthesis of silver and gold nanoparticles. Process Biochem 45: 10651071.

10. Kumar VG, Gokavarapu SD, Rajeswari A, Dhas TS, Karthick V, et al. (2011) Facile green synthesis of gold nanoparticles using leaf extract of antidiabetic potent Cassia auriculata. Colloids Surf B 87: 159-163. 
11. Smitha SL, Philip D, Gopchandran KG (2009) Green synthesis of gold nanoparticles using Cinnamomum zeylanicum leaf broth. Spectrochim. Acta A 74: 735-739.

12. Dwivedi A, Gopal K (2010) Biosynthesis of silver and gold nano particles using Chenopodium album leaf extract. Colloid Surface A: Physicochem Eng Asp 369: 27-33.

13. Li Y, Wu Y, Ong BS (2005) Facile synthesis of silver nano particles useful for fabrication of high-conductivity elements for printed electronics. J Am Chem Soc 127: 3266-3267.

14. Evanoff DD, Chumanov G (2005) Synthesis and optical properties of silver nano particles and arrays. Chem Phys Chem 6: 1221-1231.

15. Sun Y, Xia Y (2002) Shape-controlled synthesis of gold and silver nano particles. Science 298: 2176-2179.

16. Sun RWY, Chen R, Chung NPY, Ho CM, Lin CLS, et al. (2005) Silver nano particles fabricated in Hepes buffer exhibit cytoprotective activities toward HIV-1 infected cells. Chem Com 40: 5059-5061.

17. Lu L, Sun R, Chen R, Hui CK, Ho CM, et al. (2008) Silver nano particles inhibit hepatitis B virus replication. Antiviral Therapy 13(2): 253-262.

18. Sun L, Singh AK, Vig K, Pillai SR, Singh SR (2008) Silver nano particles inhibit replication of respiratory syncytial virus. J Biomed Nanotech 4(2): 149-158.

19. Baram-Pinto D, Shukla S, Perkas N, Gedanken A, Sarid R (2009) Inhibition of herpes simplex virus type 1 infection by silver nano particles capped with mercaptoethane sulfonate. Bioconjugate Chemistry 20(8): 14971502.

20. Rogers JV, Parkinson CV, Choi YW, Speshock JL, Hussain SM (2008) A preliminary assessment of silver nano particle inhibition of monkey pox virus plaque formation. Nanoscale Research Letters 3(4): 129-133.
21. KE Clemens, R Brent, J Gyuris, K Munger (1995) Dimerization of the human papilloma virus E7 oncoprotein in vivo. Virology 214: 289-293.

22. CC Baker, WC Phelps, Lindgren V, MJ Braun, MA Gonda, et al. (1987) Structural and transcriptional analysis of human papilloma virus type 16 sequences in cervical carcinoma cell lines. Journal of Virology 61(4): 962-971.

23. K Munger, WC Phelps (1993) The human papilloma virus E7 protein as a transforming and transactivating factor. Biochimica et Biophysica Acta 1155(1): 111-123.

24. Vishnu Kiran M, Murugesan S (2014) Biosynthesis of silver nano particles from marine alga Halymenia poryphyroides and its antibacterial efficacy. Int J Curr Microbiol App Sci 3(4): 96-103.

25. Vishnu Kiran M, Murugesan S (2014) Biological synthesis of silver nano particles from marine alga Colpomenia sinuosa and its in vitro antidiabetic activity. AJBBL 3(1): 1-7.

26. Vishnu Kiran M, Murugesan S (2013) Biogenic silver nanoparticles by Halymenia porphyroides and its in vitro anti-diabetic efficacy. J Chem Pharma Res 5(12): 1001-1008.

27. Barbosa MS, Edmonds C, Fisher C, Schiller JT, Lowy DR et al. (1990) The region of the hpv E7 oncoprotein homologous to adenovirus E1a and Sv40 large $\mathrm{T}$ antigen contains separate domains for $\mathrm{Rb}$ binding and casein kinase II phosphorylation. Embo Journal 9(1): 153-160.

28. Lara HH, Ayala-Nunez NV, Ixtepan-Turrent L, Rodriguez-Padilla C (2010) Mode of antiviral action of silver nano particles against HIV-1. J Nanobiotechnol 8: 1-10.

29. Shahin Gavanji, Hassan Mohabatkar, Hojjat Baghshahi, Ali Zarrabi (2014) Bioinformatics Prediction of Interaction Silver Nano particles on the Disulfide Bonds of HIV-1 Gp120 Protein. International Journal of Scientific Research in Knowledge 2(2): 67-74.

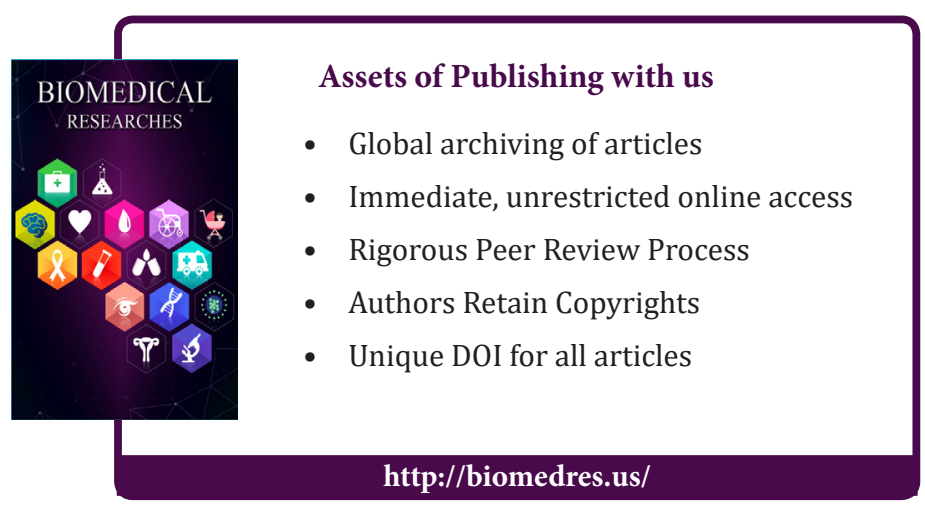

